\title{
LINGUAGENS: ABORDAGENS RELACIONADAS À FORMAÇÃO DOCENTE EM PERÍODO PANDÊMICO
}

\author{
Danieli Martins Ambrós ${ }^{1}$; Taís Steffenello Ghisleni ${ }^{2}$; Valéria lensen Bortoluzzi ${ }^{3}$
}

\section{RESUMO}

O presente artigo apresenta como tema do estudo: relevância sobre linguagem e formação docente no período pandêmico. Para fundamentar a pesquisa, questionase como problema de pesquisa: Quais os Programas de Formação Inicial de professores, voltadas às linguagens que, discutem sobre formação docente em período pandêmico? Com isso, buscou-se como objetivo geral: Revisar a literatura existente sobre os Programas de Formação Inicial de professores voltadas às linguagens a fim de, discutir sobre a formação de professores em período acadêmico. Então, para alicerçar o tema buscou-se Programas de Formação Inicial de professores como: Programa Estudantes-Convênio de Graduação (PEC-G) e Programa Educação Tutorial (PET) igualmente, uma revisão literária sobre o assunto referenciam-se autores, como: Bourdieu (2008), Pereira (2018) entre outros. Dessa forma, é possível refletir sobre formação docente e linguagem nessa fase de pandemia, buscando autores que possam mediar sobre o assunto e assim deem conta do objetivo e do problema em questão.

Palavras-chave: Pandemia; Professores; Programas de Formação Inicial.

Eixo Temático: Educação, Cultura e Comunicação.

\section{INTRODUÇÃO}

A pesquisa buscou como tema deste estudo: desvendar a relevância sobre linguagem e formação docente no período pandêmico. Nesse sentido, demonstra-se que a linguagem faz parte da formação docente na qual, a partir dela, temos 0 conhecimento adquirido por meio da linguagem, e essa comunicação acontece pela interação social das pessoas de várias maneiras, como: linguagem escrita, linguagem oral, linguagem corporal. E essa comunicação é indispensável na formação docente já que, a linguagem é uma ferramenta essencial para o ensino - aprendizagem e o

\footnotetext{
1 Autor/Apresentador - Mestranda da UFN. E-mail: danieliambros88@gmail.com

2 Professora da UFN. E-mail: taisghisleni@ufn.edu.br

3 Professora da UFN. E-mail: valbortoluzzi@ufn.edu.br
} 
desenvolvimento do aluno em sala de aula, principalmente agora nesse período pandêmico que estamos enfrentando com o Coronavírus. Visto que, com essa pandemia houve muitas mudanças em relação a educação do nosso país, especialmente ação de executar as aulas em forma remota, a qual, a formação inicial teve que se inovar.

E por esse motivo, as inovações foram as formas de comunicação que as universidades tiveram de opção para trazer os alunos para a formação inicial, produzindo assim, maneiras que chamem atenção do público como na: internet, outdoors, propagandas, métodos para cativar mais alunos. E esses métodos, principalmente agora nesse período pandêmico, convenceram muitas pessoas a ir atrás de novos conhecimentos para se aprimorarem profissionalmente já que, muitas pessoas, ao se depararem com o desemprego, devido a pandemia, tiveram que procurar alguma formação inicial para recomeçar.

Já outras mudanças em nossa educação foram os Programas de Formação Inicial de professores, da quais, já existem por bastante tempo, mas com essa pandemia, foi uma das melhores maneiras do cidadão brasileiro ingressar nas universidades e por isso, ao longo deste artigo serão comentados os seguintes Programas: Programa Estudantes-Convênio de Graduação (PEC-G) e Programa Educação Tutorial (PET). Com tudo isso, partiu-se do tema central a qual, vai ao encontro do problema de pesquisa: Quais os Programas de Formação Inicial de professores, voltadas às linguagens que discutem sobre formação docente em período pandêmico? E ao se deparar com esse questionamento buscou-se os Programas de Formação Inicial de professores que, de alguma forma, está vinculado com a comunicação, linguagens mesmo nesse período pandêmico.

E para fundamentar essas questões sobre Linguagem e formação docente, tem-se como objetivo geral o seguinte: revisar a literatura existente sobre os Programas de Formação Inicial de professores voltadas às linguagens a fim de, discutir sobre a formação de professores em período acadêmico. E para justificar essa pesquisa buscou-se realizar análises e coletas de dados que fossem significativas para área da educação, consolidando esses dados coletados para dar eficiência ao assunto e aperfeiçoamento da profissão da autora. 
Tanto a formação docente quanto a linguagem são essenciais para o desenvolvimento do ser humano, sendo assim, as competências elaboradas por meio da linguagem atribuída por um conhecimento auxiliam no desenvolvimento: intelectual, cognitivo, na memória, imaginativo, emocional e psicossocial. Para perpetuidade do assunto essa pesquisa referenciou-se com os nomeados autores como: Anastasiou (2015); Berger e Luckmann (2003); Bourdieu (2008); Nussbaum (2015); Pereira (2018); Perfeito (2007); Tardif (2002). Buscando assim, desenvolver um estudo com base sólida a partir de leituras significativas sobre linguagem e formação docente em período pandêmico para assim, demonstrar resultados eficazes que possam abranger o objetivo geral como também responder ao questionamento abordado.

\section{METODOLOGIA}

Para aperfeiçoar os estudos sobre formação docente e linguagem pensou-se numa metodologia com uma abordagem qualitativa por meio de uma pesquisa documental e bibliográfica. E para argumentar sobre os métodos utilizados para aprimorar a pesquisa temos os seguintes autores: Gil (2006) e LIMA; MIOTO (2007) e por isso, tem-se as palavras de Lima; Mioto (2007, p.41) que argumentam o seguinte: "a investigação das soluções também pode envolver a construção de um instrumento que permita pinçar das obras escolhidas os temas, os conceitos, as considerações relevantes para a compreensão do objeto de estudo".

Portanto, foi executada uma pesquisa, um estudo acerca de linguagem e formação docente onde se desenvolveu uma análise de conhecimentos e que, foi transmitida ideias, pensamentos sobre esse tema tão relevante para área da educação. Igualmente para basear os estudos dessa pesquisa, temos o documento legal na área da educação, arquivo aberto ao público e diante desse contexto, compreende-se que todos esses tipos de publicações eram importantes para o estudo dessa pesquisa e, para isso temos como uma produção de pesquisa bibliográfica o seguinte dizer:

A pesquisa bibliográfica é desenvolvida com base em material já elaborado, constituído principalmente de livros e artigos científicos.[...] A pesquisa bibliográfica também é indispensável nos estudos históricos. Em muitas 
situações, não há outra maneira de conhecer os fatos passados se não com bases em dados bibliográficos. (GIL, 2006, p.44 e 45).

Já em relação à pesquisa documental pode-se refletir melhor com os dizeres de Gil (2006) que afirma que, a pesquisa documental utiliza-se de fontes de materiais impressos, sobretudo arquivos históricos, como: arquivos de instituições de ensino, de igreja, arquivos de órgãos públicos, como também arquivos pessoais como: gravações, filmagens, boletins, etc. Então, a pesquisa documental, baseia-se em documentos ricos de dados que, tornam-se muito relevantes e essenciais para que aconteça uma pesquisa sólida e fundamentada com qualidade. Desse modo, buscouse executar um procedimento de pesquisa que desse subsídio ao tema de pesquisa que é: relevância sobre linguagem e formação docente no período acadêmico, e para isso compreendeu-se que seria interessante trazer autores que argumentassem sobre esse assunto com relevância.

\title{
FORMAÇÃO INICIAL E LINGUAGENS
}

Inicialmente destaca-se as concepções de linguagem neste estudo, dando ênfase a língua como processo de apropriação, onde o indivíduo expressa-se, criando códigos, interpretando maneiras de expor suas ideias, como a fala, gestos, olhares e para isso tem-se as palavras de Perfeito (2007) que afirma que a concepção de linguagem é considerada uma forma de manifestar, interpretar, reproduzir seus pensamentos. Em suma, é uma forma das pessoas exprimirem suas ideias, sentimentos, opiniões, das quais podem ser por meio da linguagem oral, escrita e a linguagem corporal tudo depende com quem e aonde está acontecendo essa comunicação. Para ilustrar melhor esse pensamento, temos as palavras de Pereira (2018, p.41) que argumenta o seguinte:

\begin{abstract}
A linguagem é algo inerente ao ser vivo. Essa, por sua vez, está diretamente associada ao princípio da comunicação e interação, tendo em vista os efeitos de sentidos que ocasionam em situações específicas.[...] Quando tem-se como referência a comunicação, está-se referindo, diretamente, aos elementos que estruturaram uma situação comunicativa que, juntos, elaboram discursos e propagam ideologias.
\end{abstract}

Essa ideia acima, condiz acerca das linguagens, referindo-se que a comunicação como um elemento essencial para formação docente sendo assim uma 
forma de interação e, nesse caso essa associação da comunicação e interação elaboram ideologias e discursos como na própria citação diz, elementos que vão ao encontro do questionamento em questão. Em relação a isso, pode-se dizer que ao ocorrer essas comunicações, interações dentro de Instituições de Ensino, dentro da formação inicial, temos a linguagem oral e escrita: as mensagens, códigos, conjunto de sinais, relacionadas aos diferentes grupos sociais de acordo com a "natureza sócio histórica" sendo uma ação orientada de acordo com as práticas sociais desses grupos, palavras de Perfeito $(2007$, p.827). Para dar continuidade às concepções de linguagem, relacionado à formação docente buscou-se, palavras de, Berger e Luckmann (2003) quando eles argumentam que:

A linguagem tem origem e encontra sua referência primária na vida cotidiana, referindo-se sobretudo à realidade que experimento na consciência em estado de vigília, que é dominada por motivos pragmáticos (isto é, o aglomerado de significados diretamente referentes a ações presentes ou futuras) e que partilho com outros de uma maneira suposta evidente. (BERGER E LUCKMANN, 2003, p.58).

Com esses dizeres pode-se relatar que a linguagem na formação docente se encontra na vida cotidiana dos estudantes dentro e fora das Instituições de Ensino, sendo "aglomerados de significados diretamente referentes a ações presentes e futuras", como na própria citação afirma. Comunicações, interações entre os estudantes, promovendo significados, das quais são partilhados, tendo assim trocas de ideias, opiniões, pensamentos. Desse modo, a comunicação, interação associada às trocas de ideias, tem uma relação de riqueza, um "tesouro universal", termo de Bourdieu (2008) nas quais, auxiliam no desenvolvimento: intelectual, cognitivo, na memória, imaginativo, afetivo, emocional e psicossocial.

A linguagem é um tesouro, uma descrição de uma apropriação simbólica, de um conjunto de códigos de sinais e, assim, as condições sociais da apropriação da língua, recorre de uma maneira diferente em cada ser. De maneira que, ao discutir sobre concepções sobre linguagem interligando a formação docente partiu-se a literatura existente sobre os Programas de Formação Inicial de professores, esses que podem auxiliar na formação docente no período acadêmico. 


\section{PROGRAMAS DE FORMAÇÃO INICIAL DE PROFESSORES}

Para compreender um pouco mais sobre tema central: relevância sobre linguagem e formação docente no período pandêmico pode-se dizer que, é relevante comentar acerca dos Programas de Formação Inicial de professores, voltadas às linguagens e a formação docente já que, pode-se discutir sobre os pontos que contribuem para o desenvolvimento: intelectual, cognitivo, memória, imaginativo, emocional, afetivo e psicossocial dos estudantes. Desse modo, foi escolhido dois Programas, das quais abordam assuntos recorrentes da formação docente e estão se desenvolvendo nas redes de Instituições Federais de ensino superior até mesmo nesse período pandêmico. E acerca disso, pode-se salientar que o Decreto, 끅.948, de 12 de março de 2013, o Programa Estudantes-Convênio de Graduação (PEC-G) argumenta que:

[...] Programa Estudantes-Convênio de Graduação (PEC-G), da competência da Diretoria de Desenvolvimento da Rede de Instituições Federais de Ensino Superior, no âmbito da Coordenação Geral de Assuntos Internacionais da Educação Superior (CGAI/DIFES/SESu/MEC), em parceria com o Ministério das Relações Exteriores, oferece oportunidades de formação superior a cidadãos de países com os quais o Brasil mantém acordos educacionais e culturais. Atende às seguintes estratégias do Estado Brasileiro: Relativo à Política Externa, busca intensificar a união e a integração com Estados estrangeiros e cooperar para a formação de recursos humanos de alto nível. Relativo à Política de Educação Superior, busca contribuir para o desenvolvimento intercultural e para internacionalização das IES brasileiras. [...] Indicadores de Resultados: Mais de 23.000 vagas ofertadas por IES brasileiras nos últimos 7 anos (2014 a 2020), sendo mais de 5.000 estudantes selecionados no mesmo período. Atualmente, há 1.815 alunos de 53 países diferentes regularmente matriculados em 89 IES brasileiras. Entre 2009 e 2020, mais de 2.300 alunos se formaram (BRASIL, 2020, s/p.).

Sobre essa citação pode-se afirmar que, esse Programa de Formação Inicial demonstra a oportunidade de estrangeiros estudarem em um Ensino Superior tendo assim, uma integração e comunicação entre os cidadãos dos países envolvidos nele e igualmente, demonstrando que, mesmo nesse período pandêmico foram selecionados muitos estudantes, os quais tiveram a possibilidade de ingressar em uma universidade. Onde buscam contribuir para o desenvolvimento intercultural buscando assim, intensificar a união, integração e linguagem entre os países envolvidos no Programa Estudantes-Convênio de Graduação (PEC-G). De modo que, esses estudantes vinculados ao Programa Estudantes-Convênio de Graduação (PEC- 
G), estão voltados às linguagens, a uma formação integrada, com recursos humanos de alto nível como na própria citação afirma demonstrando assim, contribuições positivas ao desenvolvimento: intelectual, cognitivo, memória, imaginativo, emocional, afetivo e psicossocial dos estudantes envolvidos.

Essas interações entre os países havendo assim, dimensões do espaço social, nesse caso, ocorrendo nas Instituições de Ensino onde sucedem comunicações, interpretações diferentes, tendo trocas de ideias, pensamentos, opiniões, entre os estudantes e professores e, assim todo esse movimento torna-se uma ferramenta essencial para o ensino - aprendizagem e o desenvolvimento do aluno em sala de aula. Logo, ao salientar acerca do tema: a relevância sobre linguagem e formação docente no período acadêmico pode-se dizer que, temos outro Programa muito importante para formação docente que é: Programa Educação Tutorial (PET), a qual discute o seguinte:

Criado pela Lei oㅜ 11.180, de 23 de setembro de 2005, e regulamentado pela Portaria no 976, de 27 de julho de 2010, o Programa Educação Tutorial (PET) destina-se a fomentar grupos de aprendizagem tutorial mediante a concessão de bolsas de iniciação científica a estudantes de graduação e bolsas de tutoria a professorestutores de grupos do PET. É da competência da Diretoria de Políticas e Programas de Educação Superior, no âmbito da Coordenação Geral de Relações Estudantis e Serviços Digitais (Dippes/CGRED). [...] Indicadores de resultados: Em 2020, R\$ 70,4 milhões alocados para execução das ações do programa. 12.332 estudantes de graduação participaram dos grupos de tutoria do PET. 897 professores mestres e doutores atuaram no programa na condição de tutor de grupo de tutoria do PET. 107.736 bolsas concedidas, sendo 98.893 destinadas a estudantes de graduação e 8.843 destinadas a professores-tutores do PET". (BRASIL, 2020, s/p.).

Neste Programa, como foi confirmado acima, são concedidas bolsas de iniciação científica, as quais, em relação a essa destinação pode-se expressar que há uma integração entre estudantes de graduação e os professores-tutores de grupos do PET. Uma união que destina-se a fomentar grupos de estudos, pesquisa, comunicação, trocas de ideias, de aprendizagem, ações relevantes para o ensinoaprendizagem e o desenvolvimento dos alunos.

Uma vez que, esse Programa apresentado, como o outro Programa já comentado neste artigo, são muito importantes para a formação inicial, mesmo nesse período pandêmico, concebendo mesmo assim bolsas científicas para incentivar, estimular outros cidadãos a procurar qualificações, cursos superiores para aprimorar seus conhecimentos. Tanto o Programa Estudantes-Convênio de Graduação (PECG) e o Programa Educação Tutorial (PET) demonstram em seus resultados que estão 
em vigência em período pandêmico, como pode-se ratificar em alguns dados como: no PET em 2020 , em plena pandemia foram concedidos $R \$ 70,4$ milhões alocados para execução das ações desse programa sendo concedidas 107.736 bolsas de iniciação científicas.

Assim, por meio desses Programas de Formação Inicial, pode-se haver tomadas de transmissão de saberes, trocas de experiências em sala de aula entre o professor titular e o graduando, partilhando trocas de ideias que podem servir para o desenvolvimento de novos professores. Uma união, integração de aprendizagem, de compartilhamento de saberes de como desenvolver uma aula interessante, produtiva, partilhando estilos de maneiras de dar aula que deram certo, mas, para isso acontecer é essencial que continue presente esses Programas nas Instituições de Ensino Superior para que, outros cidadãos procurem novos conhecimentos.

E para argumentar acerca de compartilhamento de saberes e experiências, temos as palavras de Tardif (2002) que, propõem os saberes experienciais por meio das vivências individuais e coletivas que devem ser partilhadas, tornando-se chaves para a formação de docentes. Essas vivências repartidas tornam-se uma união, integração, linguagem, compartilhamentos de saberes entre os docentes contribuindo assim para as competências que são as alavancas para força produtiva na área de trabalho escolhida pelo graduando.

Igualmente as trocas de experiências são elementos fundamentais para que, esse novo profissional, recém formado tenha um horizonte a ser seguido, auxiliando também em seu desenvolvimento: intelectual, cognitivo, imaginativo, da memória, afetivo, emocional e psicossocial dentro e fora do ambiente de trabalho, da escola. Dessa maneira, pode-se confirmar que esses Programas de Formação Inicial, integram, unem, ocorre comunicação, estudo, aprendizado, desenvolvimento de todos os envolvidos.

Por isso, esses Programas relatados ao longo deste artigo, trouxe a importância da Educação mostrando a relevância da linguagem e formação docente mesmo nesse período pandêmico já que, mesmo nessa situação o Governo Federal continua executando ações em prol da Educação. Além disso, um dos Programas de Formação Inicial dos Professores demonstrou a ideia de interação, união entre 
Estados Estrangeiros, no Programa Estudantes-Convênio de Graduação (PEC-G) e para salientar essas trocas de experiências entre os estudantes estrangeiros com os brasileiros têm-se as expressões de Nussbaum(2015) que argumenta o quanto é importante a troca de ideias com outras pessoas mantendo o clima de respeito para assim, manter um diálogo, uma linguagem pacífica e reflexiva.

E assim, para formar cidadãos mais reflexivos dando ênfase, à relevância sobre linguagem e formação docente no período pandêmico traga-se Anastasiou (2015) que apresenta dois elementos relevantes para a ação docente ao reportar-se ao ensino, o verbo apreender e a ensinagem. $O$ verbo apreender significa apropriar, assimilar mentalmente o conteúdo onde essa meta de ensino é um processo de desenvolvimento cerebral do aluno em que, ele é estimulado pelo professor.

Assim, essa ação de ensino agora não é mais "assistir aula", mas em "fazer aula" por meio de estratégias diferenciadas e efetivas facilitando o inovador modo de ensinar já que, nesse período pandêmico. De acordo com Anastasiou (2015) o processo de ensino é aplicado pelo termo ensinagem que compreende a efetiva prática social entre o professor e aluno pela ação de ensinar e de apreender.

Para que aconteça esse ensino que não é tradicional, Anastasiou (2015) insere estratégias de ensinagem, as quais não são nenhuma novidade, uma elaboração de um ensino inovador, onde o aluno apreende o conteúdo a partir das construções de relação com os outros e com o mundo. Onde os estudantes mesmo em casa tiveram que apreender o conteúdo de um modo diferenciado, por meio de interação comunicativa, afetiva, reflexiva e autônoma muitas das vezes visto que, o professor não estava presente ao seu lado o tempo todo.

Então para finalizar, depois de todas essas discussões acerca da formação docente pode-se afirmar que, a linguagem é indispensável na formação docentes e que, os dois Programas de Formação Inicial de Professores, mencionados neste estudo, reforçam e solidifica a ideia do questionamento do artigo que era: Quais os Programas de Formação Inicial de professores, voltadas às linguagens que, discutem sobre formação docente em período pandêmico? E assim, tanto os Programas de Formação Inicial dos professores voltadas a linguagem e a formação docente são fundamentais para as competências que auxiliam no desenvolvimento: intelectual, 
cognitivo, na memória, imaginativo, afetivo, emocional e psicossocial mesmo nesse período pandêmico.

\section{CONCLUSÕES/CONSIDERAÇÕES FINAIS}

Com a pesquisa, foi possível compreender acerca do tema: relevância sobre linguagem e formação docente no período pandêmico, dando ênfase a esse estudo tão relevante e fundamental para a área da educação. Nesse sentido, partiu-se do problema de pesquisa: Quais os Programas de Formação Inicial de professores, voltadas às linguagens que, discutem sobre formação docente em período pandêmico? Por isso, a linguagem é uma forma de interação importante na formação docente sendo assim, no decorrer dessa pesquisa foi possível trazer autores fundamentais sobre formação de professores como: Anastasiou (2015); Nussbaum (2015) e Tardif (2002), das quais descreveram bem o cenário da educação, fazendo muitas referências acerca do professor perante a sala de aula.

Ficando evidente tanto esses autores quanto os os Programas de Formação Inicial de professores: Programa Estudantes-Convênio de Graduação (PEC-G), Programa Educação Tutorial (PET) fizeram uma ligação voltada às linguagens sobre formação docente nesse período pandêmico que estamos vivendo. Dando ênfase também ao objetivo geral: Revisar a literatura existente sobre os Programas de Formação Inicial de professores voltadas às linguagens a fim de, discutir sobre a formação na formação de professores em período acadêmico pode-se perceber que, os autores da área de educação e linguagens que foram escolhidos para discutir acerca do assunto abordado nessa pesquisa foram de grande valia.

Portanto, a literatura abordada neste estudo foram essenciais para abranger e serem suportes importantes para formação docente. Igualmente destaca-se os Programas de Formação Inicial de professores que ao longo dessa pesquisa percebeu-se as interligações das linguagens. Assim, ficou clara a relação das linguagens com a formação docente e os Programas e por isso, é relevante salientar que esse estudo vem ao encontro da linha de pesquisa: Ensino, epistemologias e formação docente do Mestrado em Ensino de Humanidades e Linguagens-MEHL, na Universidade Franciscana. Nesse sentido, o estudo aqui realizado 
é imprescindível para a área da educação e também para as práticas pedagógicas da autora, pois agregará muito nos seus estudos ao longo do MEHL. Enfim, esse estudo buscou-se realizar análises e coletas de dados que fossem significativas para a autora a fim de, aperfeiçoar seus estudos e igualmente sofisticar sua profissão.

\section{REFERÊNCIAS}

ANASTASIOU, L.das G. C.; ALVES, L.P (Orgs.). Processos de ensinagem na universidade: pressupostos para as estratégias de trabalho em aula. Joinville, SC: UNIVILLE, 2015.

BRASIL. Ministério da Educação. Secretaria da Educação Superior. Programas e Ações/ Ministério da Educação. Secretaria de Educação Superior (Sesu). Brasília, MEC, DF, 2020. Disponível em:

https://www.gov.br/mec/pt-br/acesso-ainformacao/institucional/secretarias/secretaria-de-educacao-superior/programas-eacoes-sesu Acesso em: 14 Jul. 2021.

BERGER, P. L.; LUCKMANN, T.. Os fundamentos do conhecimento na vida cotidiana. A construção social da realidade. Petrópolis, RJ: Vozes, 2003, pp 35-68.

BOURDIEU, Pierre, 1930-2002. A Economia das Trocas Linguísticas: O que Falar Quer Dizer/ Pierre Bourdieu; prefácio Sérgio Miceli. - 2. ed., 1o reimpr. -São Paulo: Editora da Universidade de São Paulo, 2008. Disponível em: https://mega.nz/folder/HkYxgaob\#GyW4fGftU_8ABK5u0rS1hg. Acessado: 19 jun. 2021.

GIL, A.C. Como elaborar projetos de pesquisa. São Paulo: Atlas, 2006.

LIMA, T. C. S. de; MIOTO, R. C. T. Procedimentos metodológicos na construção do conhecimento científico: a pesquisa bibliográfica. Revista Katálysis, v. 10, n. SPE, p. 37-45, 2007. 
UCAÇÃO, SAÚDE

ETECNOLLGIA

26 A 28 DE OUTUBRO DE 2021

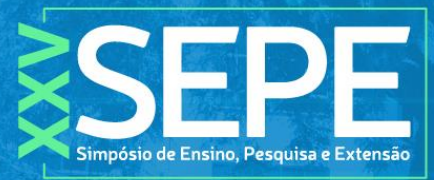

TRABAL

NUSSBAUM, M. Sem fins lucrativos: por que a democracia precisa das humanidades. São Paulo: WMF Martins. Fontes, 2015.

PEREIRA, B. G. et al. Concepções interdisciplinares sobre linguagem: dialogando com diferentes perspectivas do conhecimento. Revista São Luís Orione. V. 2, oㅜ 13, 2018.

PERFEITO, A. M. Concepções de linguagem e análise linguística: diagnóstico para propostas de intervenção. Universidade Estadual de Londrina. I Congresso latinoamericano, p. 824-836, 2007. Disponível em:

http://files.obeduc.webnode.com/200000056-

0693508863/74 Alba Maria Perfeito.pdf

Acessado: 9 ago. 2021.

TARDIF, M. Saberes docentes e formação profissional. Petrópolis, RJ: Vozes, 2002. 